\title{
FIELD MEASUREMENTS OF SNOW-DRIFT THRESHOLD AND MASS FLUXES, AND RELATED MODEL SIMULATIONS
}

\author{
JUDITH J. J. DOORSCHOT, MICHAEL LEHNING* and ANOUCK VROUWE \\ Swiss Federal Institute for Snow and Avalanche Research, Flüelastrasse 11, 7260 Davos Dorf, \\ Switzerland
}

(Received in final form 24 March 2004)

\begin{abstract}
Field measurements were carried out to calculate the threshold friction velocity for snow saltation, and mass fluxes during snow drift. The wind was measured in three components by an ultrasonic anemometer, and the mass fluxes were determined using an optical sensor ('snow particle counter'), acoustic sensors ('Flowcapt') and mechanical traps. The threshold friction velocity was found to be correlated to the grain size $\left(R^{2}=0.75\right)$. The mass flux measurements were compared with numerical simulations of snow drift, and it was demonstrated that the maximum snow transport takes place at shear stress values of roughly two times the average shear stress over $20 \mathrm{~min}$. By implementing a probability distribution for the shear stress the mass flux was simulated with only the mean measured value of the shear stress as input. This procedure enables the future use of the numerical model for operational applications.
\end{abstract}

Keywords: Field measurements, Mass flux, Saltation, Snow drift, Suspension, Threshold.

\section{Introduction}

Wind transport of snow has a major impact on the seasonal mass balance in Arctic and Antarctic areas. In Alpine terrain, the redistribution of snow by the wind is also of crucial importance for avalanche formation, and is strongly linked with the growth of vegetation. For these reasons, much work has been done in recent years to improve knowledge on this subject. Also sand drift has been investigated intensively, in particular in the field of sand saltation.

Many studies focus on numerical simulations of the physical processes (Anderson and Haff, 1991; McEwan and Willets, 1991; Naaim et al., 1998; Shao and Li, 1999; Doorschot and Lehning, 2002). Measurements of sand and snow drift have recently mainly been carried out in wind tunnels (Nalpanis et al., 1993; Nishimura et al., 1998; Nishimura and Hunt, 2000). Although these experiments are extremely valuable for testing and improving existing models, additional field measurements are needed for evaluating numerical models used for simulating snow (or sand) drift in real atmospheric turbulence. However, not many quantitative measurements from Alpine sites are available so far.

* E-mail: lehning@slf.ch

Boundary-Layer Meteorology 113: 347-368, 2004.

(C) 2004 Kluwer Academic Publishers. Printed in the Netherlands. 
Field measurements of snow drift started with the experiments of Budd et al. (1966), who used mechanical traps for measuring mass fluxes. Schmidt (1982) did some pioneering work in the development of optical snowdrift sensors. More recently, several new techniques were developed. In the Antarctic, snow-drift measurements were performed by Bintanja et al. (2001), who used a sensor based on a pulse-counting technique. Michaux et al. (2001) used an acoustic sensor for their measurements at the Lac Blanc Pass, and Jaedicke (2001) showed results from a sensor working on the same principle.

A major problem for field measurements, however, is the fact that an extensive test of the different types of sensors is needed, before the results of such measurements can be interpreted quantitatively. It should be emphasised that measuring snow drift in the outdoors may be highly complicated by disturbing influences such as low temperatures, high humidity and riming. Furthermore, high concentrations of snow may produce saturation effects in the measurements, or even complete blocking of the sensors.

A sensor evaluation was presented in Lehning et al. (2002), for windtunnel measurements (at CSTB, Nantes) using two types of acoustic sensors and one optic sensor. The sensor output was compared with mechanical traps, wind measurements and model simulations. For these measurements the optical sensor ('snow particle counter') showed good agreement with the measurements using the mechanical traps, and with the simulation results. For the acoustic sensors it is concluded that they are robust and measure autonomously, and may therefore be suitable for operational measurements in remote areas, for the benefit of avalanche warning. However, they still show some problems with the calibration, and may therefore in the current state of development not yet be suitable for research applications. The measurement techniques used for the experiments presented in this paper are based on the results of this test.

Our purpose is to evaluate a recently developed snow-drift model with field measurements; the model deals with the processes of saltation and suspension. The measurements also involve the determination of the threshold shear stress required for snow drift, since this is an important input parameter for the simulations. The numerical saltation model was presented in Doorschot and Lehning (2002), and was developed for future use in simulations of snow-height distributions in complex terrain, as well as for operational applications, such as the computation of a 'snow-drift index' for use in avalanche warnings (Lehning et al., 2002b). This snow-drift index predicts the (dimensionless) order of magnitude of the process of snow drift for given wind and snow circumstances. For such operational applications, wind data are often available only in half-hour averages. Therefore the question arises whether snow-drift simulations can be accurately performed with such data, and associated with that, which timescale is important for the 
snow-drift process. These questions are discussed, together with the evaluation of the mass-flux simulations, in Section 4.

\section{Experimental Procedure}

All field experiments were performed at the experimental site 'Versuchsfeld' of the Swiss Federal Institute for Snow and Avalanche Research. The site is situated at the Weissfluhjoch in the Parsenn area, near Davos, at $2540 \mathrm{~m}$ a.s.l., and is approximately flat; at the location of the instruments the ground has a slope of $4.5^{\circ}$. The Versuchsfeld is surrounded by mountain ridges on the west, north and east side, which may have a significant effect on local atmospheric turbulence. The predominant wind directions are from north and south at the site, and are mainly determined by topographic effects. Since it is not possible to distinguish between snow drift and precipitation in the drift measurements, experiments were only done in the absence of snow fall.

\subsection{INSTRUMENTS}

In the winter of 1999/2000, an experimental set-up was made, consisting of two acoustic snow-drift sensors ('FlowCapt'), one optical snow-drift sensor ('snow-particle counter'), three anemometers and mechanical snow traps. The emphasis of these measurements was to test the suitability of the snowdrift sensors for operational and research applications. A discussion of the test conclusions can be found in Lehning et al. (2002). However, some measurements were made focusing on the mass fluxes of snow drift in saltation and suspension.

The acoustic snow-drift sensor FlowCapt was developed by IAV Engineering (Chritin et al., 1999), and consists of a microphone inside a tube that detects the sound of impacting particles. From the signal a mass flux rate is deduced, by assuming the sound is dependent on the impact momentum. In our experiments, two sensors of this type were used: one single-segment sensor (FlowCapt100) of $1 \mathrm{~m}$ height, and one multi-segment sensor (FlowCapt520) with five segments of $0.2 \mathrm{~m}$ length each.

The snow-particle counter (SPC-S7) works on an optical method (Sato and Kimura, 1993), with a laser diode sending out a light signal, which is received by a double-split sensor. Particles passing through the laser beam cause a double peak in the detected signal. In this manner the number of particles as well as the particle size are determined. The snow-particle counter detects particles between 61 and $500 \mu \mathrm{m}$ in size, divided into 32 size classes; the results are recorded either every $1 \mathrm{~s}$ or every $10 \mathrm{~s}$. A photograph of the 


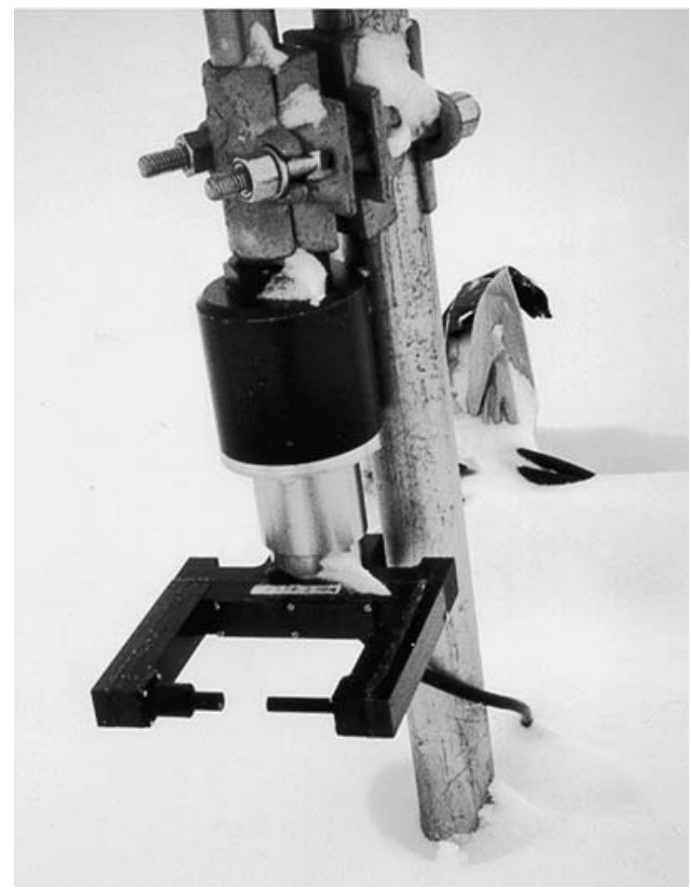

Figure 1. Picture of the optic snow-drift sensor 'snow-particle counter'.

sensor is shown in Figure 1. The experiments show that the smallest particle size consistently has the largest fraction, and that the largest particle sizes are only detected at high wind speeds. The reason for this relates to the particle segregation as a function of height, as was also shown in the wind-tunnel measurements of Nishimura et al. (1998).

The mechanical traps ('snowbags') have an inlet area of $0.00248 \mathrm{~m}^{2}$, and are fixed in the main wind direction. The anemometers ('Young-sensors') sample the wind speed every second; the wind direction is also measured. During each measurement, snow samples were taken in order to determine the average size and dendricity of the snow grains. This was done by taking photographs of the snow grains, followed by an image analysis (Fierz and Baunach, 2000). The bulk density of the snow was also measured.

During the winter of 2000/2001 the focus of the experiments was on determining the threshold conditions for snow drift and the mass fluxes in saltation and suspension. The instruments were set up at the same location as in the previous winter. The measurements were made with the snow-particle counter, the snow bags and an ultrasonic anemometer. Again, each experiment was combined with a measurement of the snow characteristics and the bulk density.

The ultrasonic anemometer (Kaijo Denki, model S-2003) measures the wind velocity in three components, as well as the air temperature. Wind 


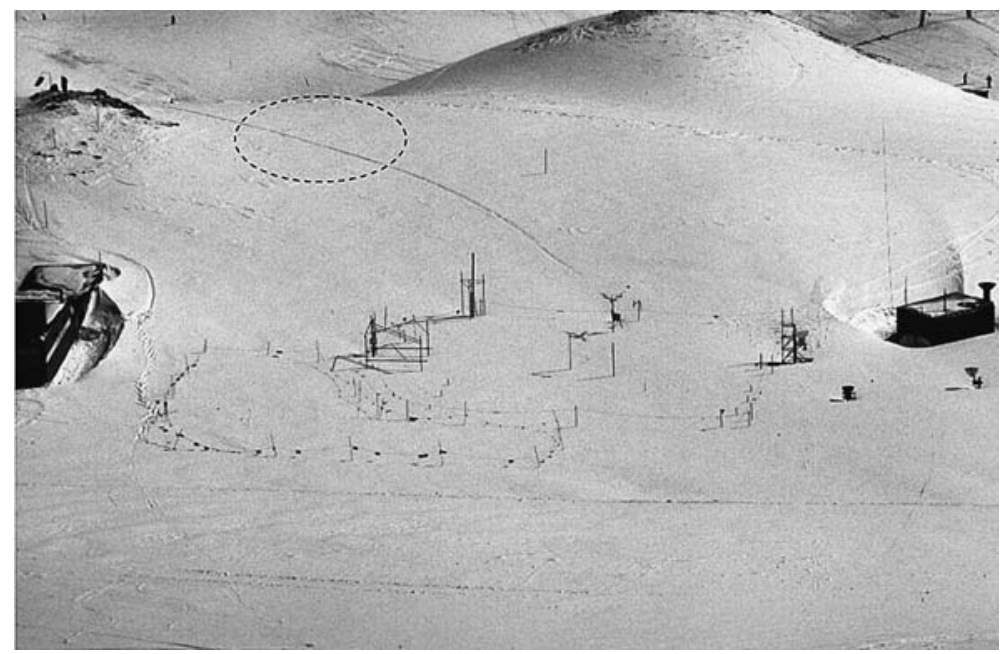

Figure 2. Photo of the 'Versuchsfeld' area where the measurements took place. The location where the snow-drift sensors were placed is indicated with the dashed circle.

speeds are measured up to $30 \mathrm{~m} \mathrm{~s}^{-1}$, with an accuracy of $0.05 \mathrm{~m} \mathrm{~s}^{-1}$. The measurements are recorded at a frequency of $20 \mathrm{~Hz}$, so that the turbulence characteristics of the wind can be taken into account.

The horizontal distance between the various sensors was about 1 to $1.5 \mathrm{~m}$. In all experiments the measurement time was short enough to ensure that the snow surface was not altered during the measurement; the sensors and the snow surface were continuously monitored during the experiments. The area in which the measurements took place is shown in Figure 2.

\subsection{DATA PROCESSING}

From the measurements with the ultrasonic anemometer the Reynolds shear stress $\tau[\mathrm{Pa}]$ is determined using the eddy correlation method (e.g., Stull, 1988),

$$
\tau=\rho_{\mathrm{a}}\left(\overline{u^{\prime} w^{\prime}}+\overline{v^{\prime} w^{\prime}}\right)
$$

where $\rho_{\mathrm{a}}$ is the density of air, and $u^{\prime}, v^{\prime}$ and $w^{\prime}$ are the deviations from the average wind speeds in the $x, y$ and $z$ directions, respectively. The averaging time must be chosen such that all relevant eddy sizes are taken into account. In atmospheric flows this averaging time is usually between $20 \mathrm{~min}$ and $1 \mathrm{~h}$.

The friction velocity $u_{*}$ is related to the Reynolds shear stress by

$$
\tau=\rho_{\mathrm{a}} u_{*}^{2} \text {. }
$$

When the eddy correlation method cannot be used, the friction velocity is determined from a profile method, viz., 


$$
u_{*}=\frac{\kappa u_{\mathrm{h}}(z)}{\ln \left(z / z_{0}\right)},
$$

where $u_{\mathrm{h}}(z)$ is the horizontal wind speed at height $z$ above the surface, $u_{*}$ is the friction velocity, $\kappa$ is the von Karman constant, and $z_{0}$ is the roughness length. Note that Equation (3) applies only in the constant flux layer, and under neutral conditions; it is also assumed that there is no need to include a zero-plane displacement.

An overview of the experiments is presented in Table I. In total, 12 experiments were carried out for measuring the total snow mass that was transported by the wind. For all experiments, except experiment number 5 (21 February 2001), the dominant wind direction was from the south. For each experiment the instrumental set-up was turned into the main wind direction.

The sonic anemometer was located at low heights over the surface to ensure that topographic effects from the surrounding mountains had no influence on

TABLE I

Overview of the field experiments done in 2000 and 2001.

\begin{tabular}{|c|c|c|c|c|c|c|}
\hline $\begin{array}{l}\text { Exp. } \\
\text { nr. }\end{array}$ & Date & Time & $\begin{array}{l}\text { Wind } \\
\text { direction }\end{array}$ & $\begin{array}{l}\text { Mean wind } \\
\text { speed }\left(\mathrm{m} \mathrm{s}^{-1}\right)\end{array}$ & $\begin{array}{l}\text { Wind meas., } \\
\text { resolution }\end{array}$ & $\begin{array}{l}\text { Height wind } \\
\text { sensor }(\mathrm{m})\end{array}$ \\
\hline 1 & 13 April 2000 & $1240-1315$ & South & 5.3 & Young, $5 \mathrm{~s}$ & 1.17 \\
\hline 2 & & $1320-1355$ & & 4.6 & & \\
\hline 3 & 16 April 2000 & $1525-1552$ & South & 5.3 & Young, $5 \mathrm{~s}$ & 1.08 \\
\hline 4 & 21 February 2001 & $1013-1243$ & North & 5.0 & $\begin{array}{l}\text { ultrasonic } \\
\text { anem., } 0.05 \mathrm{~s}\end{array}$ & 0.36 \\
\hline 5 & 27 February 2001 & $1211-1402$ & South & 4.9 & $\begin{array}{l}\text { ultrasonic } \\
\text { anem., } 0.05 \mathrm{~s}\end{array}$ & 0.21 \\
\hline 6 & & $1430-1600$ & & 4.3 & & \\
\hline 7 & 2 March 2001 & $1315-1515$ & South & 3.8 & $\begin{array}{l}\text { ultrasonic } \\
\text { anem., } 0.05 \mathrm{~s}\end{array}$ & 0.12 \\
\hline 8 & 4 March 2001 & $1300-1345$ & South & 5.4 & $\begin{array}{l}\text { ultrasonic } \\
\text { anem., } 0.05 \mathrm{~s}\end{array}$ & 0.21 \\
\hline 9 & & $1348-1431$ & & 5.7 & & \\
\hline 10 & & $1434-1534$ & & 4.9 & & \\
\hline 11 & 12 March 2001 & $1329-1417$ & South & 4.7 & $\begin{array}{l}\text { sonic anem., } \\
0.05 \mathrm{~s}\end{array}$ & 0.13 \\
\hline 12 & 22 March 2001 & $1300-1430$ & South & 4.3 & $\begin{array}{l}\text { sonic anem., } \\
0.05 \mathrm{~s}\end{array}$ & 0.16 \\
\hline
\end{tabular}


the measured shear stress at the surface. The disadvantage of this set-up is that the contribution of eddies smaller than the span width of the sonic anemometer $(0.2 \mathrm{~m})$ is not captured. At low heights of the sensor the smaller eddies may contribute significantly to the total shear stress. We try to estimate this error for our set-up by looking at the resolved fraction of the cospectral energy in comparison to the unresolved fraction. An empirical relation describing the cospectral energy between streamwise and vertical velocities as a function of height over the surface is given by (Kaimal and Finnigan, 1994; their Eq. (2.56))

$$
\frac{-f C_{u w}}{u_{*}^{2}}=\frac{12 n}{(1+9.6 n)^{7 / 3}},
$$

where $f$ is the natural frequency, $C_{u w}(f)$ is the spectral density, and $n=f z / u$ is the dimensionless frequency with $z$ the height above ground and $u$ the mean wind speed. From this equation it can be seen that a large proportion of the spectral energy originates from large eddies, and at low heights over the surface. This is mainly caused by the high wind speeds under our conditions of drifting snow. Integrating Equation (4) over the relevant eddy sizes shows that, for the experiments where the sonic anemometer was located at the lowest height (2 March and 12 March 2001) the error is up to $25 \%$ and $10 \%$, respectively. For the other experiments the spectral energy for eddies smaller than the sensor size is much smaller (less than 1\%) compared to the total spectral energy. We therefore did not apply a correction and conclude that the error arising from the senor height is not critical compared to other errors inherent in this snow-drift experiment.

As for the estimate of the measuring error in the snow-drift mass, there are several factors that may contribute to the total error. Firstly, not all snow mass is captured by the bags due to the shifting direction of the wind. This was taken into account in the simulation by reducing the mass flux depending on the wind direction. A second cause may arise from the changing snow depth during the experiment and the corresponding change of drift profile. To minimise this error, the snow bags were monitored during the experiment and the experiment was stopped if a significant change in snow depth was observed. A third error is caused by the change of trajectories due to the change of flow streamlines by the bags. The relative error from this cause is the largest at low wind speeds, whereas the mass flux is largest at high wind speeds. Therefore the largest error in the mass flux will occur in the experiments with lower wind speeds. All the errors will produce an underestimation of the measured mass flux; we estimate the error in the captured snow mass at about $10 \%$ maximum.

\section{Simulations}

The results of the field measurements were used for evaluating a recently developed saltation model (Doorschot and Lehning, 2002). Since in the field 
measurements no distinction can be made between saltating and suspended mass fluxes, the saltation model was coupled to a suspension model. The measurements were made close to the surface, so that the greatest part of the mass flux was in saltation.

Saltation is the wind transport of granular material that takes place in approximately the lowest $0.05-0.1 \mathrm{~m}$ above the surface. In the saltation layer grains follow ballistic trajectories, which are governed by inertial forces, drag forces and gravity. In the numerical saltation model, it is assumed that the system is in steady state. In this case the sum of the airborne and the grainborne shear stress is constant with height, and is equal to the total fluid shear stress above the saltation layer. The grain-borne shear stress is the vertical momentum transfer that is carried by the saltating particles. The saltating mass flux follows from this momentum balance, by computing particle trajectories and parameterising the feedback between flow and particles. For determining the feedback, a distinction is made between the cases where either aerodynamic entrainment or rebound is the dominant transport mechanism in the saltation layer. The equilibrium assumption implies an immediate response of the saltation layer to a change in wind speed. This hypothesis and its implications are studied more closely in Section 4.

Above the saltation layer is the suspension layer, where the particle concentration is significantly smaller. In this layer we regard the grains as passive tracers of the turbulent wind field. In a one-dimensional approximation, the transport of suspended particles in the atmosphere is governed by a balance between turbulent diffusion and gravitational settling. This leads to the following expression for the concentration profile (Shiotani and Arai, 1967):

$$
c(z)=c\left(z_{\mathrm{ref}}\right)\left(\frac{z}{z_{\mathrm{ref}}}\right)^{-s / \kappa u_{*}},
$$

where $c(z)$ is the particle concentration as a function of height $\left(\mathrm{kg} \mathrm{m}^{-3}\right), z_{\text {ref }}$ is a reference height and $s$ is the particle settling velocity. The one-dimensional suspension model (5) is only valid during steady state drift, over flat surfaces, and in the absence of precipitation. In complex terrain, formulations for describing the suspension layer have to be modified to take into account advective effects (e.g., Lehning et al., 2000a). Recent research has focused on the interaction between turbulence and snow drift in the suspension layer (Bintanja et al., 2000).

For finding the concentration at the reference height $z_{\text {ref }}$ a flux profile $f(z)$ $\left[\mathrm{kg} \mathrm{m}^{-2} \mathrm{~s}^{-1}\right]$ is implemented in the saltation model (Nishimura and Hunt, 2000):

$$
f(z)=\phi \exp \left(-\lambda z /\left(u_{*}^{2} / g\right)\right),
$$

where $\lambda$ is a dimensionless parameter, and $g$ is the acceleration due to gravity $\left[\mathrm{m} \mathrm{s}^{-2}\right]$. According to the wind-tunnel experiments of Nishimura and Hunt 
(2000), the parameter $\lambda$ is 0.45 for snow. The parameter $\phi\left[\mathrm{kg} \mathrm{m}^{-2} \mathrm{~s}^{-1}\right]$ can be determined if the total saltating mass flux $Q\left[\mathrm{~kg} \mathrm{~m}^{-1} \mathrm{~s}^{-1}\right]$ is known:

$$
\phi=Q\left(\frac{\lambda}{u_{*}^{2} / g}\right) \text {. }
$$

For the reference height in Equation (5) we use the height of the saltation layer $h_{\mathrm{s}}$, which is calculated from the particle trajectories. The mass concentration at the reference height $z_{\text {ref }}$ follows from Equation (6).

\section{Results}

In this section, model simulations of snow drift are evaluated against the field measurements from the experimental site. The simulated mass fluxes are compared with both instantaneous flux measurements from the snow-particle counter, and with the transported snow mass over longer times measured with the mechanical traps. The shear stress, which is needed as an input parameter for the model, is calculated with the eddy-correlation method (1), or with the profile method (3). For applying Reynolds averaging, the turbulent fluctuations must be statistically stationary over the analysed time periods (Kaimal and Finnigan, 1994), and implies that the Reynolds shear stress can only be determined over every $20 \mathrm{~min}$ to $1 \mathrm{~h}$. For investigating short term effects, we estimated the instantaneous shear stress from,

$$
\tau(t)=\rho_{\mathrm{a}}\left(u^{\prime}(t) w^{\prime}(t)+v^{\prime}(t) w^{\prime}(t)\right) .
$$

Before analysing the model simulations in comparison with field measurements, the measurements of the snow-drift threshold are discussed, since the threshold is needed as an input parameter for the saltation model.

\subsection{THRESHOLD SHEAR STRESS FOR SNOW DRIFT}

An important input parameter for the model simulations is the threshold shear stress for snow drift, i.e. the shear stress that needs to be exceeded for snow erosion to take place. For the field measurements of snow drift at the Versuchsfeld during the winter of $2000 / 2001$, the threshold was determined from the combined measurements of the ultrasonic anemometer and the snow-particle counter. A study of the threshold velocities for Antarctic snow was done by Mann et al. (2000).

Figure 3 presents an example of the number of particles, measured by the snow particle counter, as a function of the horizontal wind speed, measured by the ultrasonic anemometer. At low wind speeds, between 0 and $2 \mathrm{~m} \mathrm{~s}^{-1}$, the number of detected particles is zero or close to zero, and at higher wind speeds, starting at 2-3 $\mathrm{m} \mathrm{s}^{-1}$, the mass flux increases significantly. The other experiments 


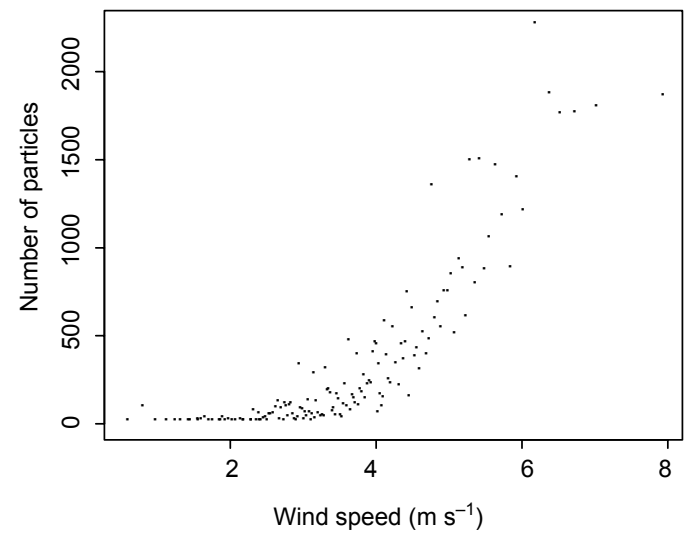

Figure 3. The number of particles, detected by the snow-particle counter, as a function of the horizontal wind speed, measured by the ultrasonic anemometer.

show a similar pattern. From Figure 3, we manually determine the threshold wind speed for this experiment as $2.5 \pm 0.5 \mathrm{~m} \mathrm{~s}^{-1}$. The threshold friction velocity follows from Equation (3), when the roughness length $z_{0}$ is known.

In very flat terrain over a smooth snow surface, the roughness height is related to the size of the particles, which tend to be the largest roughness elements. The experimental site at the Weissfluhjoch, however, has too many obstacles and surrounding topography to justify this assumption. Therefore the roughness length must be determined in a different manner.

The friction velocity can be directly determined from the three wind components measured with the ultrasonic anemometer, by combining Equations (1) and (2). Furthermore, the horizontal wind speed can be calculated concurrently, and averaged over the same time period as used for the friction velocity. Substituting the results in Equation (3), then yields an average value for the roughness length $z_{0}$.

The logarithmic wind profile (3) is valid in neutral conditions for flat terrain. Although in our experimental site there may be some deviations from this profile due to the surrounding topography, it will still be approximately valid close to the surface. For this reason, the ultrasonic anemometer was mounted close to the ground, at heights between 0.12 and $0.36 \mathrm{~m}$. For the experiments in the winter of $1999 / 2000$, where no ultrasonic anemometer was available, the threshold was determined with the data from the Young wind sensors, and the acoustic snow-drift sensor FlowCapt. For the roughness length, the average of the values from the winter 2000/2001 has been taken, and the friction velocity determined from Equation (3).

Table II shows the results of the threshold calculations for each experiment. Also the main snow characteristics, such as bulk density, grain size, dendricity and snow type, are included. The particle dendricity $d d$ is defined 
TABLE II

Results of the field experiments: snow properties, roughness length and threshold friction velocity.

\begin{tabular}{lcllllll}
\hline Date & $\begin{array}{l}\text { Tempera- } \\
\text { ture }\left({ }^{\circ} \mathrm{C}\right)\end{array}$ & $\begin{array}{l}\text { Density } \\
\left(\mathrm{kg} \mathrm{m}^{-3}\right)\end{array}$ & $\begin{array}{l}\text { Grain Size } \\
(\mu \mathrm{m})\end{array}$ & $\begin{array}{r}\text { Dendricity Type } \\
\text { of snow }(\mathrm{mm})\end{array}$ & $\begin{array}{l}z_{0} \\
\left(\mathrm{~m} \mathrm{~s}^{-1}\right)\end{array}$ \\
\hline 13 April 2000 & -3 & 120 & $550 \pm 285$ & $2.6 \pm 1.0$ & 9.0 & $0.29 \pm 0.04$ \\
16 April 2000 & -2 & - & $676 \pm 287$ & $2.5 \pm 0.8$ & $\bullet$ & 9.0 & $0.29 \pm 0.04$ \\
21 February 2001 & -6 & 177 & $540 \pm 243$ & $2.1 \pm 0.8$ & 11.3 & $0.69 \pm 0.12$ \\
27 February 2001 & -12 & 185 & $314 \pm 118$ & $2.3 \pm 1.6$ & 8.8 & $0.50 \pm 0.13$ \\
2 March 2001 & -9 & 167 & $267 \pm 174$ & $2.0 \pm 0.9$ & $\bullet$ & 1.3 & $0.21 \pm 0.05$ \\
4 March 2001 & -1 & 354 & $313 \pm 144$ & $2.7 \pm 1.6$ & 11.2 & $0.42 \pm 0.14$ \\
12 March 2001 & 2 & 167 & $440 \pm 178$ & $2.6 \pm 1.4$ & 4.9 & $0.51 \pm 0.07$ \\
22 March 2001 & -2 & 166 & $342 \pm 183$ & $2.6 \pm 1.2$ & 15.6 & $0.35 \pm 0.18$ \\
\hline
\end{tabular}

as the ratio between the perimeter $p$ of the particle and its area $a$, compared to a circle (Fierz and Baunach, 2000), viz.,

$$
d d=\frac{p^{2}}{4 \pi a} .
$$

The density was measured from the upper $0.05 \mathrm{~m}$ of the snow cover, and the snow type was determined from the snow classification code (Colbeck et al., 1991). In Table II it is seen that the roughness length stays approximately constant, with the exception of that on 2 March, where it is much lower than average. This may be caused by the relatively low wind speeds occurring that day, which may result in a larger measuring error in the ultrasonic anemometer. The measured snow density was significantly larger than the usual density of new snow $\left(\approx 20-100 \mathrm{~kg} \mathrm{~m}^{-3}\right)$, and may be an indication that snow drift was already occurring during snow fall.

Since the bulk density generally increases after snow is fallen, a positive correlation between the density and the threshold friction velocity may be expected. However, this correlation was not confirmed by our measurements. For the dendricity, the range of measured values was too low to verify a relation between dendricity and threshold. The strongest correlation found from these experiments was between the threshold friction velocity and the grain size, with a correlation coefficient of 0.75 (see Figure 4).

\subsection{SNOW DRIFT AT SMALL TIME SCALES}

The purpose of this section is to examine the characteristics of snow drift at a small time scale by measurement and by numerical simulations. This is important because the mass transport in snow drift strongly depends on the 


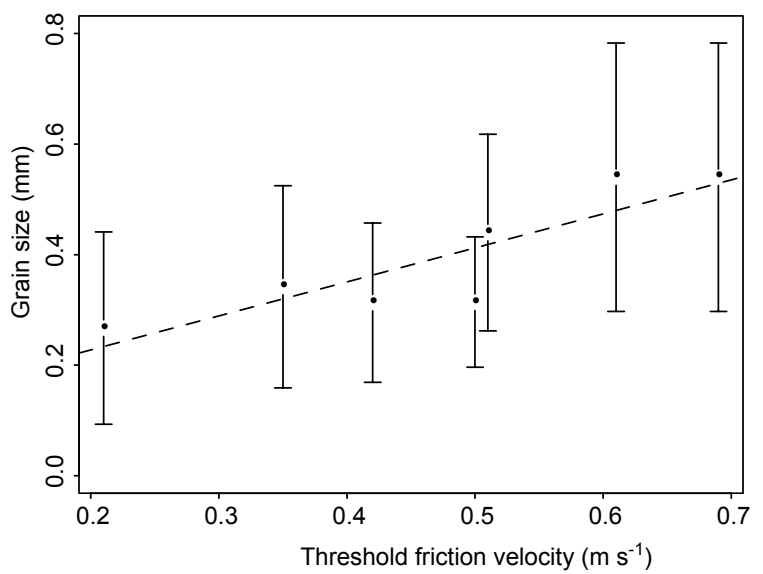

Figure 4. The relation between grain size and threshold friction velocity. The correlation coefficient is 0.76 .

occurrence of turbulent bursts. Using the high resolution wind and snowdrift data, some important characteristics of snow drift in atmospheric turbulence are identified.

Figure 5 presents the horizontal wind speed (a), the shear stress (b), and the mass flux measured by the snow-particle counter (c) as a function of time, for the experiment of 2 March 2001. It is seen that most of the peaks in wind speed and shear stress are also observed in the mass flux. There are, however, also some peaks that occur in the wind speed and shear stress, but not in the mass flux, and vice versa. This may be caused by separation in the sensors; a small eddy that reaches the snow-particle counter may not be detected by the ultrasonic anemometer, and vice versa.

As was discussed in Section 3, the model simulations are based on the assumption that the system is in steady state, and thus adjusts instantaneously to changing conditions. It was, however, suggested both by the numerical simulations of Anderson and Haff (1991) and by the wind-tunnel experiments of Butterfield (1991) that a saltating system responds to a change in wind velocity with a time lag of roughly $1-2 \mathrm{~s}$. For our field experiments, this time lag is estimated by calculating the correlation between the measured shear stress and mass flux for varying time delays. The maximum correlation was found for time lags between 0 and $1.3 \mathrm{~s}$, which is consistent with the previously mentioned studies. Remarkable is that for two experiments (4 and 12 March 2001) the correlation between shear stress and mass flux is highest when there is no time lag. Since it takes a finite time for the mass flux to adjust to the flow, it may be that at short time scales our model simulations overestimate of the mass flux during an increase in wind speed, and underestimate during decelerating flow. 

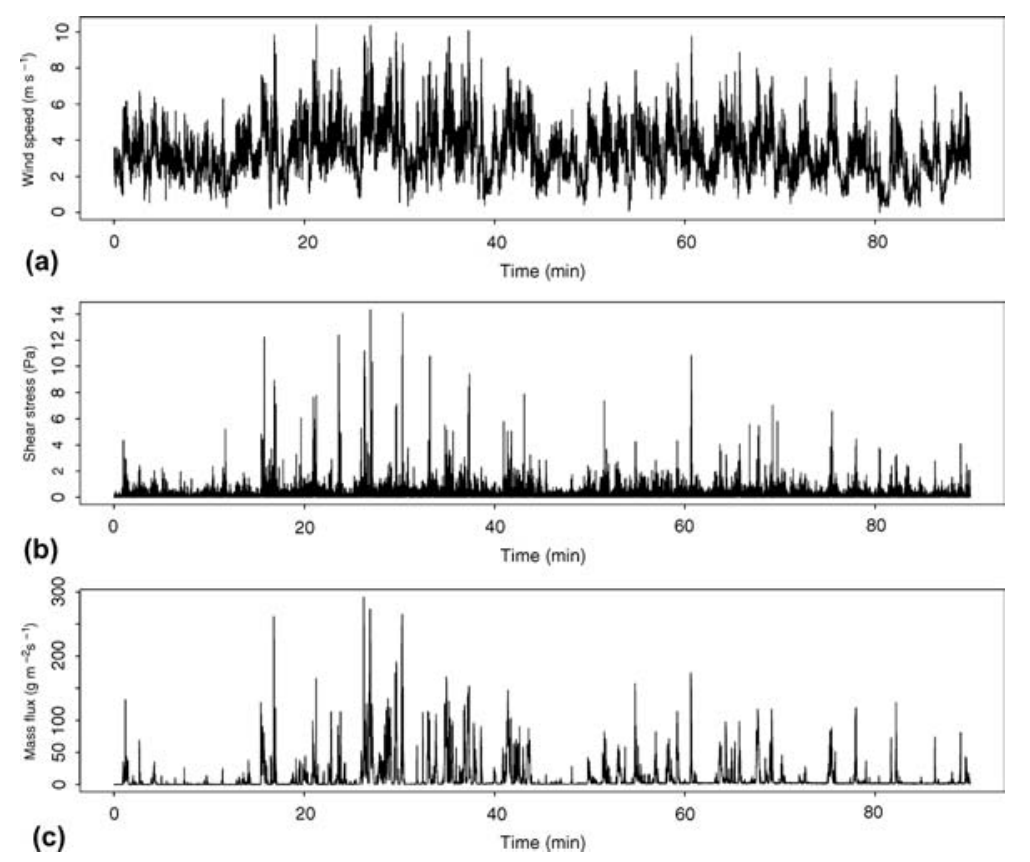

Figure 5. The horizontal wind speed (a) and shear stress (b) measured by the ultrasonic anemometer, and the mass flux (c), measured by the snow-particle counter, plotted against time, for 2 March 2001, 1310-1440.

One other issue concerning snow-drift time scales in field experiments, is the average duration of the drift episodes. The measurements from the snowparticle counter indicate that, on average, the (short-term) drift episodes last 9.1 s. Furthermore, in our experiments $97 \%$ of the snow mass is transported during drift episodes longer than $5 \mathrm{~s}$, and $93 \%$ of the mass is transported in drift episodes of longer than $10 \mathrm{~s}$.

Finally, in Figure 6 the mass flux measured by the snow-particle counter is plotted against the horizontal wind speed measured by the ultrasonic anemometer, for the experiment of 4 March 2001. The solid line shows the simulated mass flux as a function of the wind speed, assuming a logarithmic wind profile; at high wind speeds $\left(8-10 \mathrm{~m} \mathrm{~s}^{-1}\right)$, the measurements show lower mass fluxes than the simulations. This may be caused by saturation effects of the snow-particle counter, i.e. the 'view' of the receiver may be blocked when the particle concentration is high. It may, however, also be the case that in nature there exist saturation effects that are not yet taken into account in the model, for example caused by inter-particle collisions. If airborne inelastic particles, such as new snow particles, collide energy will be extracted from the saltating system, which may result in a decrease of the mass flux. An analysis of the potential effects of inter-particle collisions in saltation is given in Sørensen and McEwan (1996). 


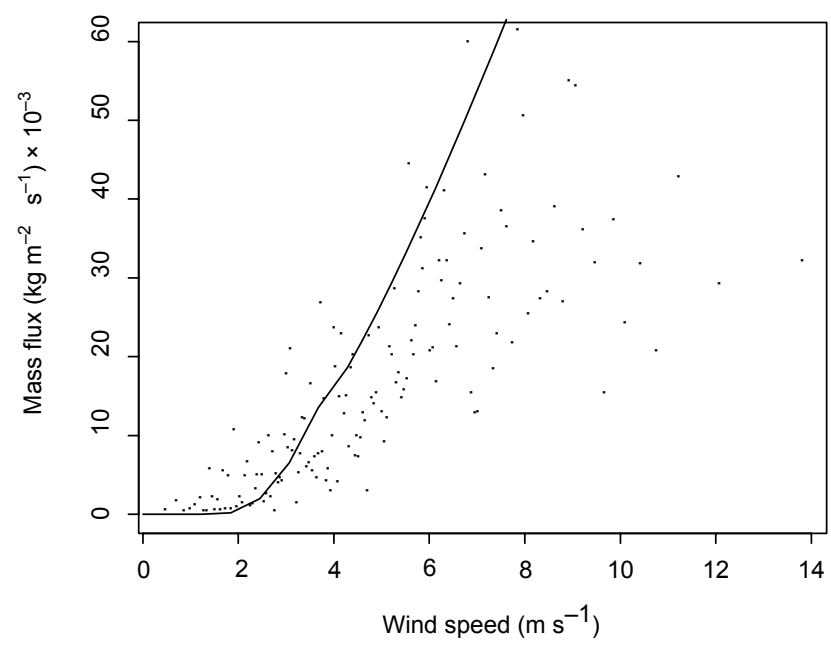

Figure 6. The mass flux measured by the snow-particle counter as a function of the wind speed. The solid line is the simulated flux.

\subsection{TIME-INTEGRATED SNOW MASS TRANSPORT}

The mechanical traps measure the total transported mass over longer time periods. The numerical model is integrated with the shear stress data obtained from the measurements of the ultrasonic anemometer, for validating whether the transported snow mass is accurately simulated.

One of the most important goals of these experiments is to verify whether the equilibrium saltation model can be applied for practical applications, i.e. for situations where wind velocity data are only available every $20 \mathrm{~min}$ or less. Therefore, the simulations are made with the shear stress average over 20 min as input. The results are presented in Figure 7, which shows a comparison between simulated and measured masses of wind-transported snow, for all experiments listed in Table I. The measured mass on the horizontal axis is the total snow mass, captured by the lowest snowbag. The dashed line represents the case where the simulated mass is equal to the measured snow mass. The correlation between measured and simulated snow mass is 0.64 ; furthermore, it is seen that the simulated snow mass is generally underestimated. It occasionally even occurs that the mean shear stress is lower than the threshold, although it can be seen that snow drift occurred. This observation may be related to the often heard claim that the maximum wind peaks, rather than the average wind velocity, are responsible for the mass transport in drifting snow. This issue is discussed more closely in the next section. 


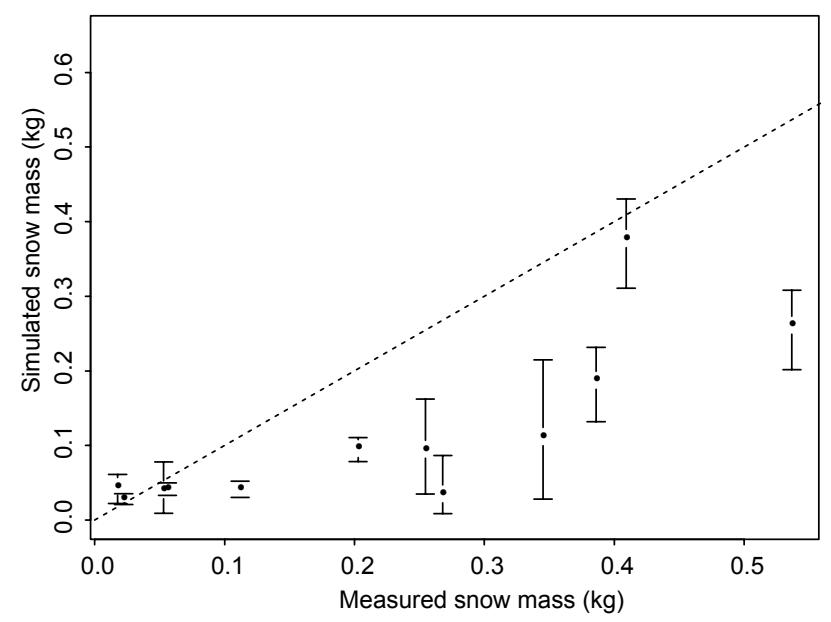

Figure 7. Simulated snow mass plotted against the measured snow mass for the lowest snowbag. The model was run once for every $20 \mathrm{~min}$ during the experiment. The solid line represents the case that the simulated mass flux is equal to the measured mass flux.

\subsection{TIME-INTEGRATED MASS TRANSPORT: STATISTICAL APPROACH}

In Figure 8 the structure of the shear-stress data over $20 \mathrm{~min}$ is examined. On the $x$-axis is the shear stress, and the $y$-axis represents the probability that the shear-stress value on the $x$-axis is exceeded by the instantaneous, measured shear stress in these $20 \mathrm{~min}$. This is shown for four different experiments, and for each it is seen that the probability of exceeding a certain value of the shear stress decreases rapidly, and then approaches a value of zero. The curves are well approximated by an exponential decay, as shown by the dashed lines in Figure 8:

$$
P\left(\tau_{\mathrm{m}}>\tau\right)=\exp (-C \tau)
$$

where $\tau_{\mathrm{m}}$ is the measured value of the shear stress, and $C$ is a constant for a single experiment. The value of $C$ for a certain experiment can be determined from the relation between the mean shear stress $\tau_{\text {mean }}$ and the probability distribution (10):

$$
\tau_{\text {mean }}=\int \tau \cdot \frac{\partial P}{\partial \tau} d \tau
$$

Integrating and rewriting yields:

$$
C=\frac{1}{\tau_{\text {mean }}}
$$

As a next step, this probability distribution is implemented in the numerical model. In this way we can investigate qualitatively the distribution 

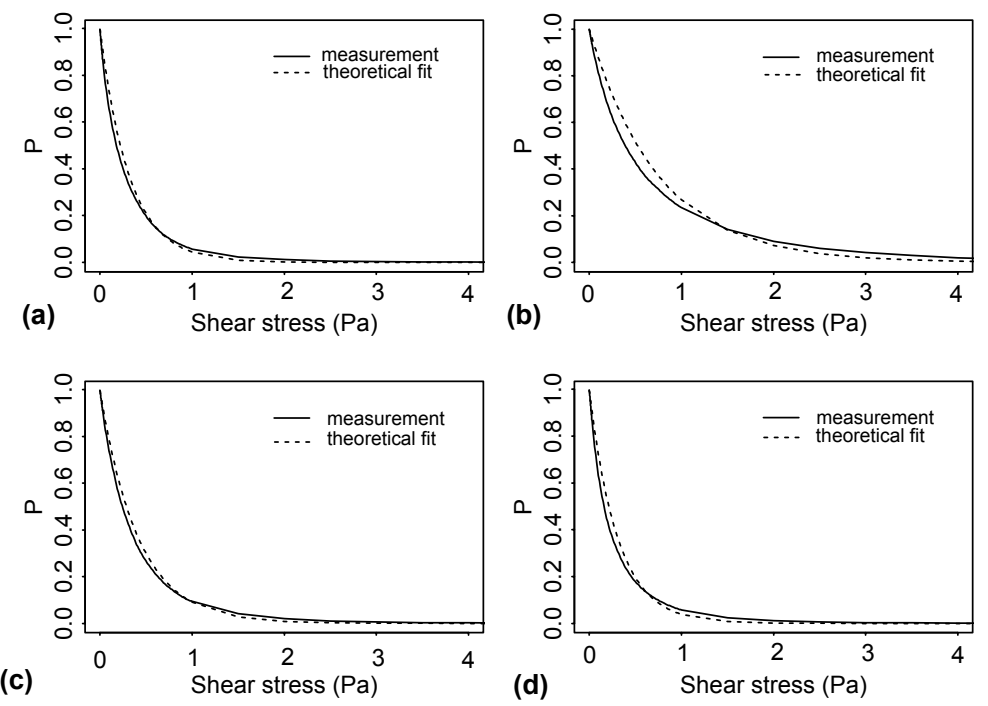

Figure 8. Measured and theoretical probability distribution of the shear stress for the experiments of 21 February 2001 (a), 4 March 2001 (b), 12 March 2001 (c) and 22 March 2001 (d). $P$ on the $y$-axis is the probability that a certain value of the shear stress is exceeded.

of the transported mass as a function of the shear stress. Whereas the probability distribution of the shear stress shows an exponential decay, the mass flux increases non-linearly as a function of the shear stress, when the threshold is exceeded.

The combination of these characteristics is illustrated in Figure 9, which represents part of the measurements for 21 February 2001. The solid line is produced by using the probability distribution (10), and the points are from the simulation over the same time period, where the model is run with the $20 \mathrm{~Hz}$ data. When the threshold shear stress is exceeded, the total transported mass increases sharply, due to the high probability of having this low shear stress. After the maximum, the total transported mass decreases again. At these high values of the shear stress the mass flux is high, although the probability function has very small values. For very high values of the shear stress the mass flux deceases, since the probability that these shear stress values occurs decreases to zero. The scatter that is observed in the high resolution simulation is caused by fluctuations in the wind direction. At high shear stresses, the points from the high resolution simulation are in general higher than the solid line from the 20-min simulation. The explanation for this may lie in the 20-min averaging of the wind direction: at high wind velocities, the wind generally is from the main direction.

In Figure 9 a maximum in the transported mass occurs in the 20-min simulation at a shear stress of $0.96 \mathrm{~Pa}$. In the same manner, the shear stress at 


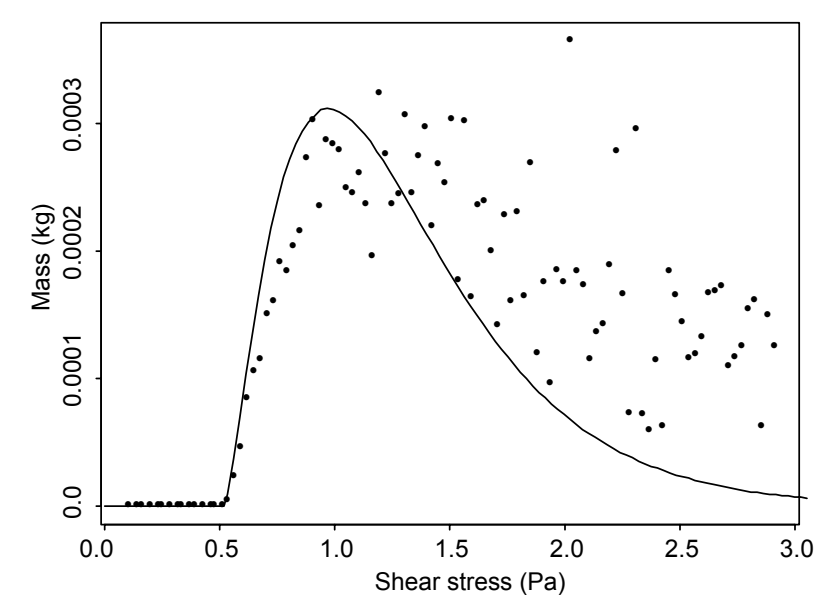

Figure 9. The total transported mass as a function of the shear stress. The points are produced by simulations from $20-\mathrm{Hz}$ data; the solid line is for simulations using the probability distribution (10).

which the maximum transport occurs is determined for all 20-min time periods in the experiments. The results are presented in Figure 10. An approximately linear relation is observed between the mean shear stress and the shear stress for the maximum transport; the scatter is caused by the differences in wind direction. On average, the maximum mass transport occurs at a shear stress of 2.05 times the mean shear stress.

Finally, the total mass transport is simulated for all field experiments by using the parameterisation (10). The simulated transported snow mass is plotted against the measured transported snow mass (in the lowest snowbag) in Figure 11. The correlation coefficient for this figure is 0.72 . An important conclusion, following from these simulations, is that the transported snow mass can be simulated with only the time-averaged shear-stress data as input.

\section{Discussion}

A major unknown factor in the snow-drift process is threshold wind speed at which saltation initiates. It is commonly known that snow type and other snow properties have a strong influence on the threshold (Schmidt, 1980), but its exact value must often be guessed in snow-drift simulations (e.g. Gauer, 1999). In these experiments the threshold wind speed was measured by combining three-dimensional wind measurements with snow-drift measurements at high time resolution. Although some scatter is observed in these measurements in natural atmospheric turbulence, the correlation in the data is high enough to determine the threshold with this method. From these 


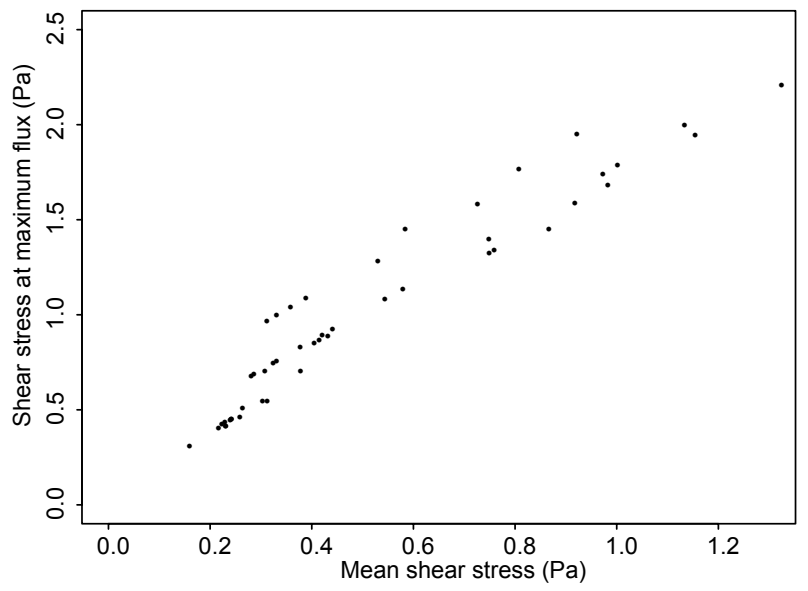

Figure 10. The shear stress at which the maximum mass transport occurs, plotted as a function of the mean shear stress over $20 \mathrm{~min}$.

experiments threshold friction velocities were found between 0.21 and $0.69 \mathrm{~m} \mathrm{~s}^{-1}$. In our measurements the threshold friction velocity is correlated to the grain size, although for verifying relations between threshold and particle dendricity or bulk density, more data are needed.

An interesting issue, when comparing wind-tunnel observations with our field measurements, is the difference in the roughness length. A relation that

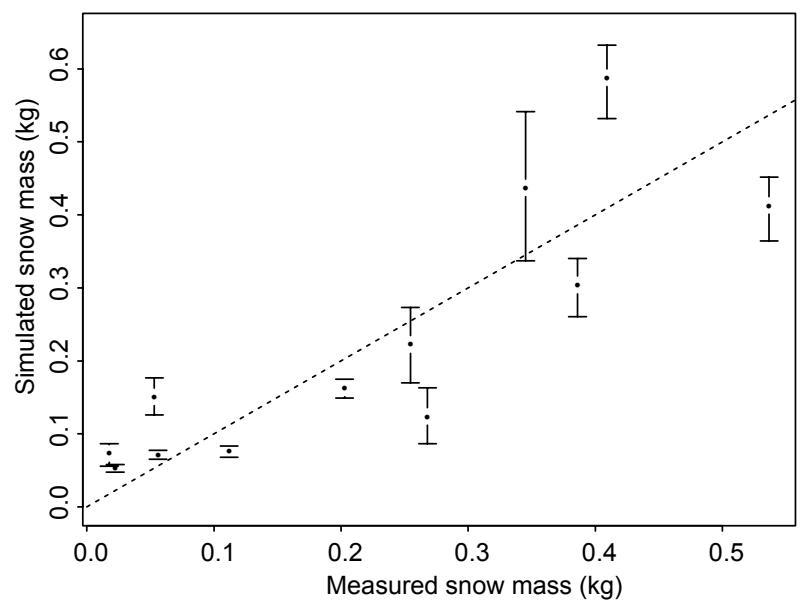

Figure 11. Simulated snow mass plotted against the measured snow mass for the lowest snowbag. The model was run once for every 20 min during the experiment, using the probability distribution (10). The solid line represents the case that the simulated mass flux is equal to the measured mass flux. 
is frequently used for describing the roughness length over water or blowing snow is that of Charnock (1955):

$$
z_{0}=\alpha \frac{u_{*}^{2}}{g},
$$

where $\alpha$ is a constant and $g$ is the acceleration due to gravity. The idea behind this equation is that the roughness increases due to the saltating grains, and the roughness length should be proportional to the height of the saltation layer. With a value for $\alpha$ of 0.016 , as measured by Chamberlain (1983), the roughness length has an order of magnitude of a few millimetres. Our field measurements, however, show much higher values of about $10 \mathrm{~mm}$. The reason for this is that at our experimental site the roughness length is mainly determined by surrounding topography and obstacles, rather than by the size of the snow grains. Also smaller topographic features on the surface, such as snow ripples, may be important.

This may also lead to a difference in the way that mass fluxes should be simulated. Both in numerical simulations (McEwan and Willets, 1991) and in wind-tunnel measurements (Nemoto and Nishimura, 2001) it was shown that the total shear stress increases with the development of saltation. This increase in the shear stress is caused by the mutual feedback between air flow and the saltation layer after the increase in roughness. This mechanism may, however, play a much smaller role during saltation in atmospheric flow near mountainous terrain, considering that the roughness length we measured is already greater than the roughness of a saltation layer. In the saltation model no increase in shear stress is taken into account.

In the numerical model a distinction is made between the cases where either aerodynamic entrainment or rebound is the dominant process in the saltation layer (Doorschot and Lehning, 2002). In the presented simulations the model indicates aerodynamic entrainment as the dominant process for all experiments. This may be explained by the relatively low density and high dendricity that was measured for the snow particles. The experiments all took place soon after snowfall, when the particles are still too dendritic and inelastic to rebound over the surface.

When using a numerical saltation or suspension model for simulating mass fluxes in atmospheric turbulence, consideration has to be given to the timescales that are important for the snow-drift process. For such simulations, the shear stress is needed as an input parameter. The Reynolds shear stress is determined by averaging wind data over $20 \mathrm{~min}$ to $1 \mathrm{~h}$. In nature it is, however, observed that saltation occurs in turbulent waves and bursts, and is a highly intermittent process. This makes it questionable whether the timescale used for Reynolds averaging is also decisive for the mass transport of snow by the wind. This contrast is reflected in our simulation results: it is seen 
that the maximum transport does not occur at the mean shear stress, but at roughly twice its value.

It therefore seems likely that the snow-drift process is better captured by analysing it at smaller time scales. The model has the implicit assumption that the saltating system responds instantaneously to changing conditions, which may cause a deficiency between measurements and simulations at short time scales. In our measurements a time lag between shear stress and drift signal of between 0 and $1.3 \mathrm{~m} \mathrm{~s}^{-1}$ is observed. The results of the simulations presented in Figure 11 may however be an indication that the effects of this time lag on the mass-flux average out over longer times. Furthermore, it was shown in Doorschot and Lehning (2002) that the effect of the feedback of particles on the airflow starts to become important when the process of rebound becomes dominant over aerodynamic entrainment. In the presented simulations aerodynamic entrainment is, however, the most important process, which may also suggest that at smaller time scales the error in the simulations stays relatively small. Finally, it was shown that short term effects can also be taken into account by implementing a probability distribution for the shear stress. In this manner, mass-flux simulations can be performed with only the average shear stress as input. This result is important for enabling the use of the model for operational applications, where often only average wind data are available.

In future, the numerical model will be used for simulating snow-height distributions in Alpine terrain after a snow-drift episode. Preliminary results of such simulations have been presented in Lehning et al. (2000a). With the presented measurements the saltation model has been evaluated in flat terrain. For assessing the model in complex terrain, measurements of mass fluxes in snow drift also need to be carried out on uphill and downhill slopes. For steep mountains, it is often observed that boundary-layer separation and the creation of a cavity occur in the leeward slope near the ridge. In these regions, it may be that suspension is far more important than saltation, due to the high turbulence intensity and the highly irregular snow patterns (e.g., cornices). Further down the lee it is however often seen that large ripples develop, which indicates that saltation occurs. The ripple wavelength in these slopes is generally larger than in flat terrain $(\approx 0.5-1 \mathrm{~m})$. This observation is likely to be related to the trajectory length of saltating grains, which is increased on downhill slopes by the more dominant gravity forces. In this situation the particles will also be accelerated more than in flat terrain, which may suggest that the process of rebound could then become dominant over aerodynamic entrainment.

\section{Acknowledgements}

The authors wish to thank W. Ammann, T. Russi and J. Rhyner for initiating and supporting this work. We would also like to thank Charles Fierz, 
Christian Sigrist, Fabienne Perret, Martin Hiller, Franz Herzog and Reto Wetter for their support with the field measurements. Furthermore, we are grateful to Vincent Chritin and the company IAV Engineering for the use of the FlowCapt sensors. The project is funded by the Swiss Federal Institute for Snow and Avalanche Research, as part of the Swiss Federal Institute for Forest, Snow and Landscape Research.

\section{References}

Anderson, R. S. and Haff, P. K.: 1991, 'Wind Modification and Bed Response during Saltation of Sand in Air', Acta Mech. (Suppl.) 1, 21-52.

Bintanja, R.: 2000, 'Snowdrift Suspension and Atmospheric Turbulence. Part I: Theoretical Background and Model Description', Boundary-Layer Meteorol. 95, 343-368.

Bintanja, R., Lilienthal, H., and Tüg, H.: 2001, 'Observations of Snowdrift over Antarctic Snow and Blue-Ice Surfaces', Ann. Glaciol. 32, 168-174.

Budd, W.F., Dingle, W. B. J., and Radok, U.: 1966, 'The Byrd Snow Drift Project: Outline and Basic Results', in M. J. Ruben, (ed.), Studies in Antarctic Meteorology, Antarctic Research Series 9, 71-134.

Butterfield, G. R.: 1991, 'Grain Transport Rates in Steady and Unsteady Turbulent Airflows', Acta Mech. (Suppl.) 1, 97-122.

Chamberlain, A. C.: 1983, 'Roughness Length of Sea, Sand and Snow', Boundary-Layer Meteorol. 25, 405-409.

Charnock, H.: 1955, 'Wind Stress on a Water Surface', Quart. J. Roy. Meteorol. Soc. 81, 639640.

Chritin, V., Bolognesi, R., and Gubler, H.: 1999, 'FlowCapt: A New Acoustic Sensor to Measure Snow Drift and Wind Velocity for Avalanche Forecasting', Cold Reg. Sci. Technol. 30, 125-133.

Colbeck, S. C., Akitaya, E., Armstrong, R., Gubler, H., Lafeuille, J., Lied, K., McClung, D., and Morris, E.: 1991, The International Classification of Seasonal Snow on the Ground, The International Commission on Snow and Ice of the International Association of Scientific Hydrology, 23 pp.

Doorschot, J. and Lehning, M.: 2002, 'Equilibrium Saltation: Mass Fluxes, Aerodynamic Entrainment and Dependence on Grain Properties', Boundary-Layer Meteorol. 104, 111130.

Doorschot, J., Raderschall, N., and Lehning, M.: 2001, 'Measurements and One-Dimensional Model Calculations of Snow Transport over a Mountain Ridge', Ann. Glaciol. 32, 153-158.

Fierz, C. and Baunach, T.: 2000, 'Quantifying Grain Shape Changes in Snow Subjected to Large Temperature Gradients', Ann. Glaciol. 31, 439-444.

Gauer, P.: 1999, 'Blowing and Drifting Snow in Alpine Terrain: A Physically-Based Numerical Model and Related Field Measurements', Ph.D. Dissertation, ETH Zürich, Switzerland, $128 \mathrm{pp}$.

Jaedicke, C.: 2001, 'Acoustic Snowdrift Measurements: Experiences from the FlowCapt Instrument', Cold Reg. Sci. Technol. 32, 71-81.

Kaimal, J. C. and Finnigan, J. J.: 1994, Atmospheric Boundary Layer Flows: Their Structure and Measurement, Oxford University Press, Inc., New York, 289 pp.

Lehning, M., Doorschot, J., Raderschall, N., and Bartelt, P.: 2000a, 'Combining Snow Drift and SNOWPACK Models to Estimate Snow Loading in Avalanche Slopes', in E. HjorthHansen, I. Holand, S. Loset, and H. Norem (eds.), Snow Engineering, Balkema, Rotterdam, pp. 113-122. 
Lehning, M., Doorschot, J., and Bartelt, P.: 2000b, 'A Snowdrift Index based on SNOWPACK Model Calculations', Ann. Glaciol. 31, 382-386.

Lehning, M., Naaim, F., Naaim, M., Brabec, B., Doorschot, J., Durand, Y., Guyomarc'h, G., Michaux, J. -L., and Zimmerli, M.: 2002, 'Snow Drift: Acoustic Sensors for Avalanche Warning and Research', Natural Hazards Earth System Sci. 2, 121-128.

Mann, G. W., Anderson, P. S., and Mobbs, S. D.: 2000, 'Profile Measurements of Blowing Snow at Halley, Antarctica', J. Geophys. Res. 105, 24491-24508.

McEwan, I. K. and Willets, B. B.: 1991, 'Numerical Model of the Saltation Cloud', Acta Mech. (Suppl.) 1, 53-66.

Michaux, J. -L., Naaim-Bouvet, F., and Naaim, M.: 2001, 'Drifting-Snow Studies over an Instrumented Mountainous Site: II. Measurements and Numerical Model at Small Scale', Ann. Glaciol. 32, 275-280.

Naaim, M., Naaim-Bouvet, F., and Martinez, H.: 1998, 'Numerical Simulation of Drifting Snow: Erosion and Deposition Models', Ann. Glaciol. 26, 191-196.

Nalpanis, P., Hunt, J. C. R., and Barrett, C. F.: 1993, 'Saltating Particles over Flat Beds', J. Fluid Mech. 251, 661-685.

Nemoto, M. and Nishimura, K.: 2001, 'Direct Measurement of Shear Stress during Snow Saltation', Boundary-Layer Meteorol. 100, 149-170.

Nishimura, K. and Hunt, J. C. R.: 2000, 'Saltation and Incipient Suspension above a Flat Particle Bed below a Turbulent Boundary Layer', J. Fluid. Mech. 417, 77-102.

Nishimura, K., Sugiura, K., Nemoto, M., and Maeno, N.: 1998, 'Measurements and Numerical Simulations of Snow-Particle Saltation', Ann. Glaciol. 26, 184-190.

Sato, T. and Kimura, T.: 1993, 'Field Test of a New Snow-Particle Counter (SPC) System', Ann. Glaciol. 18, 149-154.

Schmidt, R. A.: 1980, 'Threshold Wind-Speeds and Elastic Impact in Snow Transport', J. Glaciol. 26, 453-467.

Schmidt, R. A.: 1982, 'Vertical Profiles of Wind Speed, Snow Concentration, and Humidity in Blowing Snow', Boundary-Layer Meteorol. 23, 223-246.

Shao, Y. and Li, A.: 1999, 'Numerical Modelling of Saltation in the Atmospheric Surface Layer', Boundary-Layer Meteorol. 91, 199-225.

Shiotani, M. and Arai, H.: 1967, 'On the Vertical Distribution of Blowing Snow', in H. Oura (ed.), Physics of Snow and Ice, Vol. 1, Sapporro, Hokkaido University, Institute of Low Temperature Science, 1075-1083.

Sørensen, M. and McEwan, I.: 1996, 'On the Effect of Mid-Air Collisions on Aeolian Saltation', Sedimentology 43, 65-76.

Stull, R. B.: 1988, An Introduction to Boundary-Layer Meteorology, Kluwer Academic Publishers, Dordrecht, $666 \mathrm{pp}$. 